Function and Disability Journal ISSN: 2588-6304

Original Article

\title{
Investigating the Effect of Participation-based Individualized Occupational Therapy on Functional Mobility of Children with Cerebral Palsy in School: A Single-blind Randomized Clinical Trial
}

\author{
Atefeh Kalooti ${ }^{1}$, Mehdi Alizadeh Zarei ${ }^{2 *}$, Malek Amini
}

1. MSc. Student, Occupational Therapy Department, School of Rehabilitation Sciences, Iran University of Medical Sciences, Tehran, Iran

2. Rehabilitation Research Center, Occupational Therapy Department, School of Rehabilitation Sciences, Iran University of Medical Sciences, Tehran, Iran

\begin{tabular}{l} 
Article Info \\
\hline Received: 2018/07/29 \\
Accepted: 2018/10/06 \\
Published Online: 2018/12/15 \\
DOI: \\
How to Cite This Article \\
.Kalooti, A. Alizadeh Zarei, \\
M. Amini, M. Investigating the \\
Effect of Participation-based \\
Individualized Occupational \\
Therapy on Functional Mobility \\
of Children with Cerebral Palsy \\
in School: A Single-blind Ran- \\
domized Clinical Trial Function \\
and Disability Journal. 2018 \\
(Automn) Vol 1. No 4. Pages: \\
62-70
\end{tabular}

Use your device to scan and read the article online

\section{ABSTRACT}

Background and Objectives: Cerebral palsy is a non-progressive disorder in the growing brain that disrupts movement and ultimately limits the individual's performance and participation in a variety of areas, such as everyday life, play, and school activities. Individualized occupational interventions help these children receive appropriate services and supports based on their needs, abilities, and disabilities. Current research aimed at investigating effect of individualized occupational therapy interventions on mobility in children with cerebral palsy in the schools.

Methods: This is a Single-blind randomized clinical trial, in which 18 children with cerebral palsy at ages 6-12 were selected using convenience method, and were divided into control and intervention groups using block randomization method. During the research period, the control group like before the research received the conventional occupational therapy interventions for 5 weeks and 12 sessions. The intervention group received occupational interventions based on the individualized appropriate goals. Both groups were assessed by School Function Assessment (SFA).

Results: The average age of participants was 10.17 years old. Of these children, $52 \%$ used wheelchair .Difference in changes of mobility variables was significant between control and intervention group $(P<0.05)$.

Conclusion: The results showed that individual occupational therapy based on participation of children with cerebral palsy in exceptional schools had significant impact on mobility of children in non-academic activities of the school, which requires further studies.

Keywords: Individual occupational interventions, School-based occupational therapy, Cerebral palsy, Mobility

Mehdi Alizadeh Zarei, Rehabilitation Research Center, Occupational Therapy Department, School of Rehabilitation Sciences, Iran University of Medical Sciences, Tehran Iran Email: Alizadeh.m@ iums.ac.ir, Tel: 09123070056

Copyright (C) 2018, Function and Disability Journal. This is an original open-access article distributed under the terms of the Creative Commons Attribution-noncommercial 4.0 International License which permits copy and redistribution of the material just in noncommercial usages with proper citation.

\section{Introduction}

Cerebral palsy is a well-recognized neurodevelopmental condition beginning in early childhood and persisting through the lifespan. These disorder disrupt the person's motor control and they occur in the early years of life (Bax et al., 2005).

The overall incidence of cerebral palsy has been reported to be 2.11 in all live births (Oskoui, Coutinho,
Dykeman, Jetté, \& Pringsheim, 2013). Other reports have been reported between 2 to 6 cases per 1,000 live births (Robertson, 2003).. Children with cerebral palsy (CP) experience motor impairments, as well as deficits in other domains, which impact on their ability to move, solve problems, communicate, and socialize. Therefore these children may be at risk for less participation in school. Participation is defined as 
63. Investigating the Effect of Participation-based ...

taking part or being involved in everyday life activities and roles (Majnemer, 2008). School participation is a complex issue with some variables that makes it difficult to study by rehabilitation experts. School participation as one of the occupational participations needs many abilities, especially mobility (Schenker, Coster, \& Parush, 2005).

Occupational therapists who work for individuals' health are a unique group and their field of work is expanding rapidly. Such changes in the health system have led to the fact that the therapists can work in social environment of customers so they can help children in their schools (Beckett, 1981).

In 1975, in the USA, children with special needs lost the opportunity to study at school for two reasons: first, children with special needs were driven out of ordinary schools; and second, the children who came to ordinary schools received training and services not tailored to their needs. Finally, it was argued that like other healthy children, children with special needs, have the right to strengthen their talents, and teachers, parents and other people should provide an opportunity for these children to gain success at school and in life. The principle is currently in the personal law with the Individuals with Disabilities Education Act (IDEA), which aims to improve the educational status of children with special needs from birth to age 21 (Avery, Russell, \& Rosenbaum, 2013). The principles of this contract represent a way to educate children with special needs who must receive appropriate education and training (Katssiyannis, Yell, \& Bradley, 2001). Individualized Education Programs (IEP) was established in order to receive appropriate services for the needs of children at school, in which the tasks of experts with children are identified in the school environment. The goal of the IEP, which is a coherent and systematic program, is to engage individual goals in educational programs rather than parenting goals (Hanna \& Rodger, 2002).

Children with disabilities should be able to perform functional activities as well as academic activities in the school environment, but most of them have difficulty in participating in classes and learning and pro- moting their knowledge due to physical, cognitive and social problems. Reducing these functional problems or their compatibility is one of the main elements of social programs (Coster, Mancini, \& Ludlow, 1999).

Kardos et al. (2005) found that only 30\% of occupational therapists in the school believed that their work in exceptional schools was effective, and a large percentage of them, despite having good knowledge of working with disabled children and being familiar with the IDEA rules in the environment of school,didn't use this knowledge (Kardos \& White, 2005). Adolphson et al. (2017) concluded that planning the intervention individually for each student can be more effective (Adolfson, Johnson, \& Nilsson, 2017).Considering that occupational interventions in the schools have drawn attention recently, and the fact that children with disability have the right to use educational opportunity like ordinary children, and since the occupational therapy intervention programs are limited in Iranian schools, despite the increasing number of children with disabilities and as these children are deprived of this opportunity, as well as limited number of studies in this regard in Iran, current research was designed and conducted aiming at investigating the effect of individual occupational therapy interventions on the mobility domain of children with cerebral palsy in schools.

\section{Materials and Methods}

\section{Trial Design}

This is a single-blind randomized clinical trial, which investigated effect of individual occupational therapy interventions based on participation of children with cerebral palsy at exceptional schools. The assessments were done before interventions and two months (at the end of interventions) and four months (follow-up) after interventions. The parents signed the consent form before initiation of interventions. The trial design is illutrated in Figure 1.

\section{Randomization}

18 children with cerebral palsy were selected using block randomization method, and then divided into control and intervention groups. The participants 


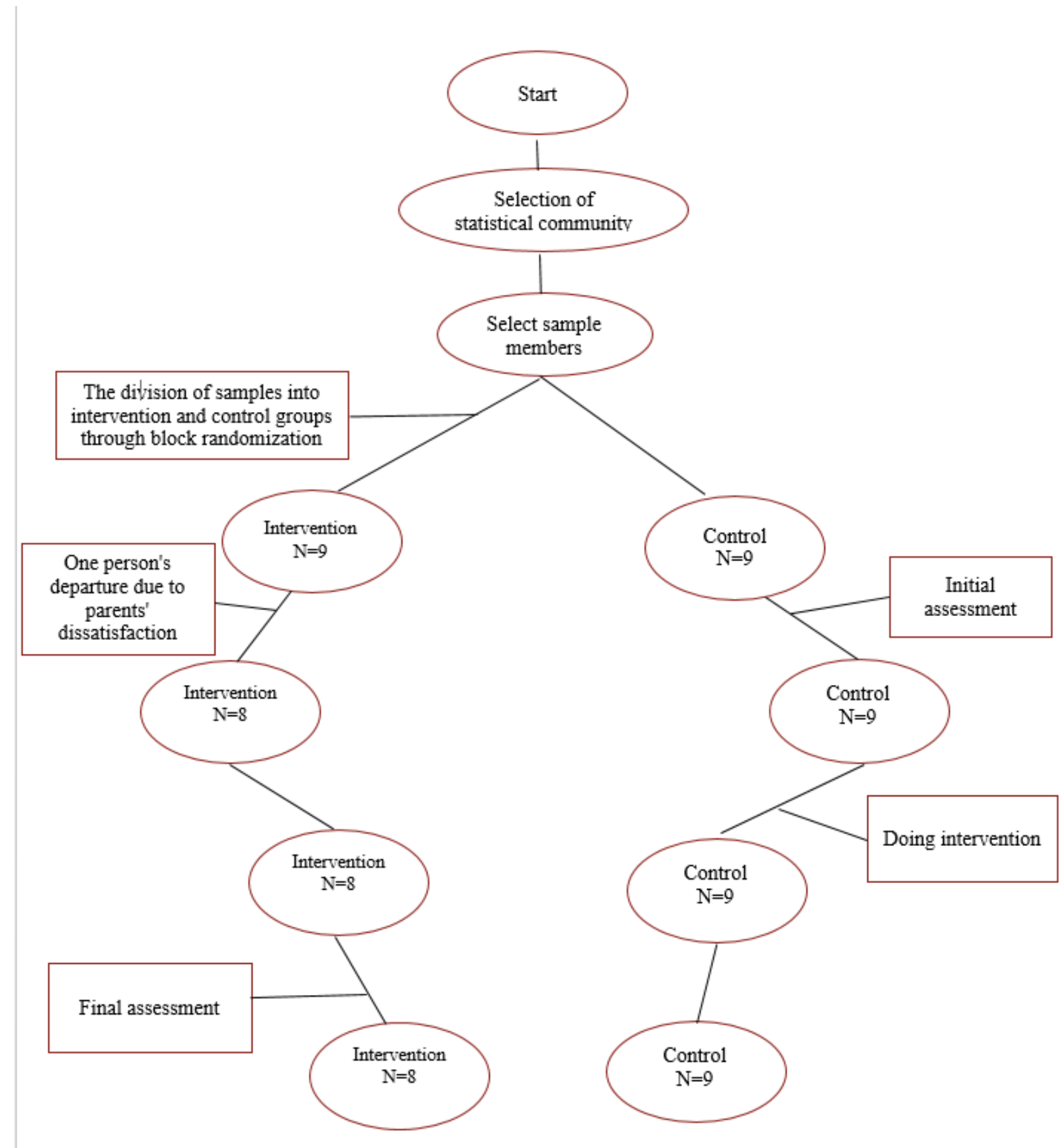

Figure 1. The trial design

were divided into eight blocks considering number of Gross Motor Function Classification System (GMFCS), and there were two participants in each block. The allocation of participants was done using computer random numbers by an independent therapist. During the study one child was excluded from the intervention group because of dissatisfaction of parents for participation in this plan. Thus, nine children were in control group and 8 ones in the control group.

\section{Participants}

The parents signed consent form and the interven- tion method and its purpose was explained to them. The sample was 17 children aged 6-12 with cerebral palsy. The sampling was done using convenience method according to the inclusion and exclusion criteria as follow: Inclusion criteria were intelligence score above 70, GMFCS score 2 and above, MACS score 1 to 3 , score of eating and drinking scale 1 to 3 . Exclusion criteria were family unwillingness to cooperate and lack of child participation in interventions.

\section{Setting}

The research was conducted in Sorush exceptional 
65. Investigating the Effect of Participation-based ...

school in Tehran in 2018 and it was approved under the ethical code of: IR.IUMS.REC.1397.

\section{Intervention}

During the intervention, the control group received the traditional occupational therapy (including stretching, muscular enhancement, balance and walking exercises), and the intervention group also received individualized occupational therapy interventions.

In the individualized occupational therapy intervention, the therapist specified the child's mobility items in the SFA. He considered the items in which the child did not receive total score. These items were logically formed as specific, measurable, attainable, realistic and timely (SMART) goals. The specified items were investigated and discussed in a session with the teacher and parents. The Goals of each child were separately selected given his capability level and intervention duration (12 sessions, 5 weeks).

Following determining the individualized intervention plan, the therapist started the plan for 12 sessions for each child with an approach to achieve specified goals. At the beginning and end of interventions, 17 children were assessed by the SFA. In the intervention group, SFA test was run for follow-up 2 months after the interventions ended.

\section{Outcome Measurement}

The demographic questionnaire included information such as age, gender, grade, entry method and mobility. Before selecting samples, The GMFCS was used to determine the gross motor skill level and the MACS was performed to determine children's hand function. The IQ was determined by the Sparkle test and the Eating and Drinking Classification System measured the eating and drinking skills in students. The SFA tool, which fully assesses school participation, was considered as the basis for determining goals and interventions.

\section{School Performance Assessment (SFA)}

Coster et al. (1998) conducted a School Performance Evaluation Test (SFA) to raise the awareness of therapists about the performance of children at school. Its purpose is to assess the functional skills required for primary school students (Hawng, Davies, Taylor, \& Gavia, 2002). SFA is a good tool for professional therapists and other professionals to prepare individual therapeutic programs for children with special needs. In other words, they can suggest IEP programs and measure the effect of treatment. The SFA consists of

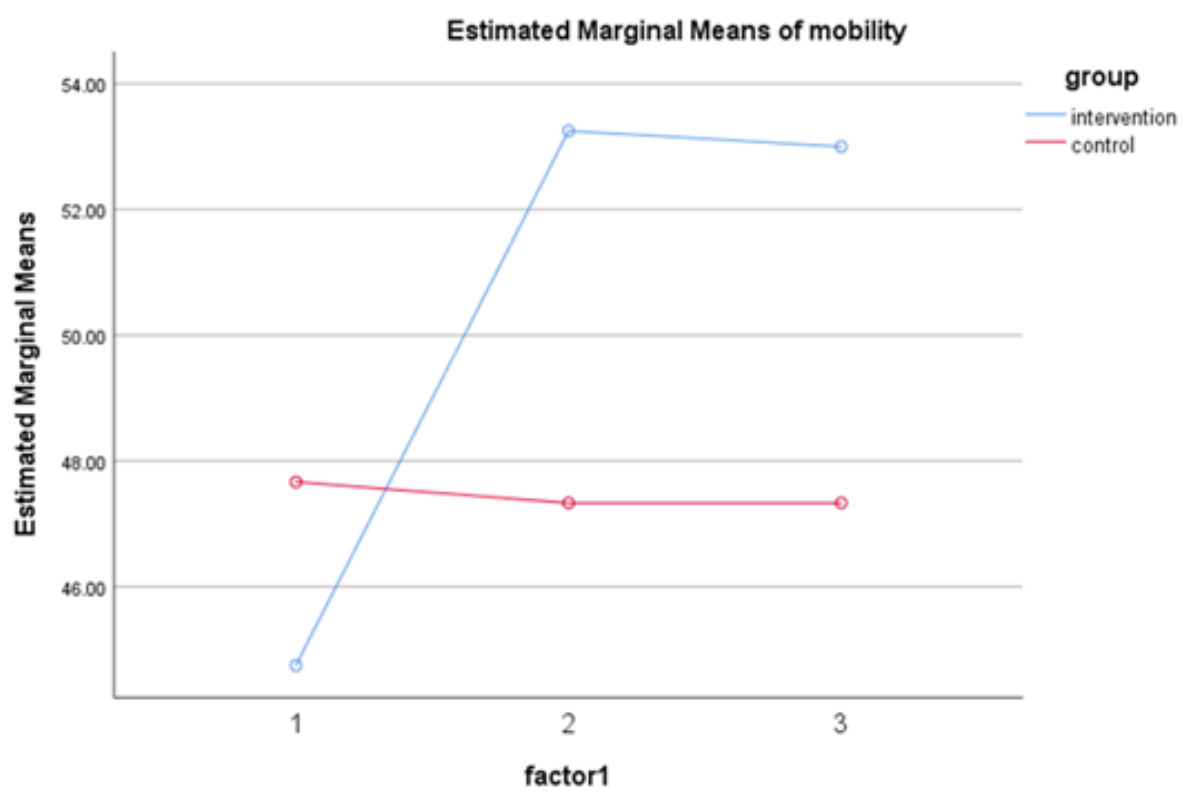

Figure 2. The estimated marginal means of mobility 
three parts:

1. Participation, which assesses the integrity of the child in six main school headquarters. These settings include regular and special classes, playgrounds, going to school, using the bathroom, going to class and food time;

2. Support for tasks that assess the compliance and assistance required for school activities. It is evaluated in the areas of assistance and compliance;

3. Functional performance that assesses the ability to perform the required activities in the school environment. This includes the ability to move in school and in the classroom, using school tools, communicating with others, following school rules and communication needs (Davis, Soon, Young, \& ClaausenYamaki, 2004).

The validity and reliability of this tool for Iranian children was measured by Alizadeh and colleagues in 2018 (Kouhbanani, Zarei, Lajevardi, Rahim zadegan, \& Shojaei, 2018). In addition, the credibility of this tool for cripplings in Iran was measured by Rahim Zadegan et al. (Rahimzadegan, Zarei, Amini, Kouhbanani, \& Shojai, 2017).

GMFM is an 88-item evaluation scale designed to evaluate gross motor function in children with cerebral palsy. To save time, the 66th version was used (Wei et al., 2016). The validity of this tool was measured by Salehi and his colleagues in Iran (Salehi et al., 2015).

GMFCS is a standard observational classification system that divides children with cerebral palsy based on gross motor abilities, limitation of gross motor function, and the need for technology and auxiliary equipment at five levels. Level 1 shows maximum independence in engine performance and Level 5 shows minimum independence in engine performance (Dehghan, Abdolvahab, Bagheri, \& Dalvand, 2001). The validity of this tool was reviewed by Riahi et al. in 2013 (Riyahi, Rassafiani, \& Bineh, 2013).
MACS is designed by Ellison in 2006, and is designed to classify the ability of children with cerebral palsy to control objects with hands. This system of classification for showing the child's ability, not his maximum capacity, reflects the skill of both hands of the child (Elissan et al., 2006). Validity and reliability of this tool in Iran were measured by Riahi et al. in 2013 (Riyahi, Rassafiani, Akbarfahimi, Sahaf, \& Yazdani, 2013).

The Sparkle cognitive classification system consists of six elements that classify children's cognitive levels according to descriptive indicators at three levels below 50, 50-70 and above 70. These items are asked from the families (Fakharynia, Rassafiani, Sourtiji, Jalili, \& Bakhshi, 2017).

Eating and Drinking Classification System: This tool was developed by Sellers et al. in 2014 and has acceptable reliability and validity (Sellers, Mandy, Pennington, Hankins, \& Morris, 2014). This includes five levels that classify the safety and efficiency of the ability to eat and drink in children with cerebral palsy. Level 1 shows eating and drinking as efficient and level 5 shows an inability to eat and drink. The validity of this tool in Iran was evaluated by Riahi et al. in 2018 (Riyahi, Rassafiani, Yazdani, \& Mradzadeh, 2018).

\section{Statistical Method}

Data obtained from the assessments were analyzed and investigated by SPSS 21 (SPSS Inc., Chicago, IL., USA). Kolmogorov Smirnov test was used to test the data distribution. Independent t-test (for variables with normal distribution) and Mann-Whitney U test (for variables with non-normal distribution) were used to determine the difference between the two groups.

\section{Results}

Intervention and control groups included 17 children with cerebral palsy at grades 2-5 in exceptional school. Average age of participants was 10.17 years. The mobility way of children was independent walking, walk-

Table 1. Significance level of changes in mobility variable between control and intervention groups

$\begin{array}{ccc}\text { mobility } & \text { Intervention } & 8.2 \\ & \text { Control } & -0.3\end{array}$

\section{2} 0.3 8.5 P-value $<0.01$ 
67. Investigating the Effect of Participation-based ...

er, and wheelchair, but percentage of children moving with wheelchair was more than others (52\%). MACS score varied between 2 and 3, and GMFCS score varied between 2, 3, and 4. EDACS score was between 1 and 3 .

Results indicated that with individualized occupational therapy interventions in school, significant difference was observed between control and intervention groups in mobility function $(P<0.01)$ (Figure 2 )

\section{.Discussion}

Current research aimed at investigating the effect of individualized occupational therapy interventions on mobility of children with cerebral palsy at school. Findings indicated that an individualized occupational therapy plan based on participation of children with cerebral palsy in exceptional schools significantly influenced mobility and increased capability of the child in these cases. It seems that if the interventions continue in this way while lasting for 6 months or longer, probability for significant changes in physical tasks is more, but this claim needs more studies. In a study by Missiuna et al. (2011) it was found that if the occupational therapy interventions are run in group in schools, better outcomes would be obtained in improvement of physical skills, and if these interventions are done with presence of at least one peer, it would have better impact on the total physical balance and skills (Missiuna et al., 2012). In addition, Novak et al. investigated effect of occupational therapy home programs in 36 children with cerebral palsy at school age. The therapeutic program was similar to our study, i.e., educating the activity, adaptation of the environment, and training the parents. Following the interventions, performance of the child and satisfaction of parents in intervention group was better than control group (Novak, Cusik, \& Lannin, 2009).The results of the statistical analysis in the current study showed that individual interventions led to an increase in the GMFM score in children with cerebral palsy in exceptional schools, and this was in line with the findings by Stiller (2009) (Stiller, Marcoux, \& Olson, 2003), which showed that performing performance-based occupational therapy interventions in children with cerebral palsy at exceptional schools improves GMFM score and the performance.

The findings also indicated that individualized occupational therapy interventions caused improvement in eating skill in children with cerebral palsy, which is consistent with findings by Tyler and Kahn. They showed that specific education is effective in improving eating and playing skill in children with cerebral palsy (Tyler \& Khn, 1976).

In the study by Rostami et al. (2010) effect of adapting the environment on the results of occupational therapy in children with cerebral palsy was studied, and they performed the movement therapy in both the clinic and home. The results showed that the recovery in the group that received the interventions at home was higher, so the familiar environment would improve the outcome and better results. This result is consistent with the findings of current study that the school environment improves the learning of school skills (Rostami et al., 2010).

\section{Limitations}

The limitations of this study included the lack of collaboration of occupational therapists working in the school, which led the research team to use a volunteer therapist for implementing the interventions. The other limitation was absence of female students in the selected school, and the interventions were just implemented on the male students. In addition, lack of complete cooperation of parents and involvement of children in other treatments during the interventions were among other research limitations.

\section{Recommendations}

The researchers who aimed at implementing interventions on participation children in exceptional schools are recommended to classify the interventions at three groups, and evaluate effect of group, individualized, and general interventions separately. It is suggested that female students are included in the research samples in the future studies. Selection of samples from more schools can provide a better statistical population and will be more representative. Implementing this type of study for children with other problems except cerebral palsy can provide new results. In addition, it is suggested that researchers apply one-year goals that set 
for IEP interventions, and long-term intervention.

\section{Conclusion}

Results of current study indicated that individualized occupational therapy based on participation of children with cerebral palsy in exceptional schools significantly influenced mobility and increased capability of the child in these cases. The parents and teachers reported occupational therapy interventions very useful and promising, and believed that initiation of these pro-

\section{References}

Adolfsson, M., Johnson, E., \& Nilsson, S. (2017). Pain management for children with cerebral palsy in school settings in two cultures: action and reaction approaches. Disability and rehabilitation, 1-11.

Avery, L. M., Russell, D. J., \& Rosenbaum, P. L. (2013). Criterion validity of the GMFM-66 item set and the GMFM-66 basal and ceiling approaches for estimating GMFM-66 scores. Developmental Medicine \& Child Neurology, 55(6), 534-538.

Bax, M., Goldstein, M., Rosenbaum, P., Leviton, A., Paneth, N., \& Dan, B. (2005). Proposed definition and classification of cerebral palsy. Developmental medicine and child neurology, 47(8), 571-576.

Beckett, S. A. (1981). survey presenting the current role of the occupational therapist in the Canadian elementary school system. Canadian Journal of Occupational Therapy, 48, 218-220.

Coster, W. J., Mancini, M. C., \& Ludlow, L. H. (1999). Factor structure of the school function assessment. Educational and psychological measurement, 59(4), 665-677.

Davies, P. L., Soon, P. L., Young, M., \& Clausen-Yamaki, A. (2004). Validity and reliability of the School Function Assessment in elementary school students with disabilities. Physical \& occupational therapy in pediatrics, 24(3), 23-43.

Dehghan, L., Abdolvahab, M., Bagheri, H., \& Dalvand, H. (2011). Inter rater reliability of Persian version of Gross Motor Function Classification System Expanded and Revised in patients with cerebral palsy. Daneshvar, 18(91), 37-44.

Eliasson, A. C., Krumlinde-Sundholm, L., Rösblad, B., grams as general plans in exceptional schools can have considerable impact on education of these children.

\section{Acknowledgment}

The authors thank all families who participated in this study. Also we acknowledge funding support of IUMS Vice Chancellor for Research \& Technology..

\section{Conflict of Interest Statement}

The authors had no conflict of interest to declare.

Beckung, E., Arner, M., \& Öhrvall, A. M. (2006). The Manual Ability Classification System (MACS) for children with cerebral palsy: scale development and evidence of validity and reliability. Developmental medicine and child neurology, 48(7), 549-554.

Fakharynia, F., Rassafiani, M., Sourtiji, H., Jalili, N., \& Bakhshi, E. (2017). Comparison of the Effectiveness of Group-based Handling Training and Individualized Handling Training on the Quality of Life in Mothers of 1-6-Year-Old Children with Cerebral Palsy. Journal of Rehabilitation Medicine, 6(2), 91-101.

Hanna, K., \& Rodger, S. (2002). Towards family-centred practice in paediatric occupational therapy: A review of the literature on parent-therapist collaboration. Australian Occupational Therapy Journal, 49(1), 14-24.

Hwang, J. L., Davies, P. L., Taylor, M. P., \& Gavin, W. J. (2002). Validation of School Function Assessment with elementary school children. OTJR: Occupation, Participation and Health, 22(2), 48-58.

Kardos, M., \& White, B. P. (2005). The role of the schoolbased occupational therapist in secondary education transition planning: A pilot survey study. American Journal of Occupational Therapy, 59(2), 173-180.

Katsiyannis, A., Yell, M. L., \& Bradley, R. (2001). Reflections on the 25th anniversary of the Individuals with Disabilities Education Act. Remedial and Special Education, 22(6), 324-334.

Kouhbanani, N. G., Zarei, M. A., Lajevardi, L., Rahimzadegan, H., \& Shojaei, A. (2018). The Reliability of the Persian Version of the School Function Assessment in Iranian Students 6 to 12 Years Old in Tehran Schools. Middle East Journal of Rehabilitation and Healt, (In Press). 
69. Investigating the Effect of Participation-based ...

Majnemer, A., Shevell, M., Law, M., Birnbaum, R., Chilingaryan, G., \& Rosenbaum, P. (2008). Participation and enjoyment of leisure activities in school-aged children with cerebral palsy. Developmental Medicine \& Child Neurology, 50(10), 751-758.

Missiuna, C. A., Pollock, N. A., Levac, D. E., Campbell, W. N., Whalen, S. D. S., \& Bennett, S. M. (2012). Partnering for change: An innovative school-based occupational therapy service delivery model for children with developmental coordination disorder. Canadian Journal of Occupational Therapy, 79(1), 41-50.

Novak, I., Cusick, A., \& Lannin, N. (2009). Occupational therapy home programs for cerebral palsy: double-blind, randomized, controlled trial. Pediatrics, 124(4), 606-614.

Oskoui, M., Coutinho, F., Dykeman, J., Jetté, N., \& Pringsheim, T. (2013). An update on the prevalence of cerebral palsy: a systematic review and meta-analysis. Developmental Medicine \& Child Neurology, 55(6), 509-519.

Rahimzadegan, H., Zareai, M. A., Amini, M., Kouhbanani, N. G., \& Shojaai, A. (2017). Psychometric properties of the Persian version of school function assessment (SFA) in 6 to 12-year-old children with physical disabilities. Middle East J Rehabil Health Stud.

Riyahi, A., Rassafiani, M., AkbarFahimi, N., Sahaf, R., \& Yazdani, F. (2013). Cross-cultural validation of the Persian version of the Manual Ability Classification System for children with cerebral palsy. International Journal of Therapy and Rehabilitation, 20(1), 19-24.

Riahi, A., Rassafiani, M., \& Binesh, M. (2013). The crosscultural validation and test-retest and inter-rater reliability of the Persian translation of parent version of the Gross Motor Function Classification System for children with Cerebral Palsy. Journal of Rehabilitation, 13(5), 25-30.

Riahi, A., Rasafiani, M., Yazdani, F., Moradzadeh, A. (2018). Psychometric evaluation of Persian version of the classification system for eating and drinking ability in children with cerebral palsy in Iran. Arak Medical University Journal, 20 (11).

Robertson, C.M., Ricci, M.F., O’Grady, K., Oskoui, M., Goez, H., \& Yager, J.Y. (2003). Prevalence Estimate of Cerebral Palsy in Northern Alberta: Births. Canadian Journal of Neurological Sciences, 44(4), 366-374.
Rosatami, H., Azizi, R., \& Khayat Zade, M. (2010). The effect of treatment environment on results of therapeutic motion along with restriction in children with cerebral palsy of hemiplegia. Mahname Daneshvar Pezeshki. Shahed University ,18(19).

Salehi, R., Keshavarz, A., Negahban, H., Saeedi, A., Shiravi, A., \& Ghorbani, S. (2015). Development of the Persian Version of Gross Motor Function Measure-88 (GMFM-88): A Study of Reliability. Trends in Medical Research, 10(3), 69-74.

Sellers, D., Mandy, A., Pennington, L., Hankins, M., \& Morris, C. (2014). Development and reliability of a system to classify the eating and drinking ability of people with cerebral palsy. Developmental Medicine \& Child Neurology, 56(3), 245-251.

Schenker, R., Coster, W., \& Parush, S. (2005). Participation and activity performance of students with cerebral palsy within the school environment. Disability and rehabilitation, 27(10), 539-552.

Stiller, C., Marcoux, B. C., \& Olson, R. E. (2003). The effect of conductive education, intensive therapy, and special education services on motor skills in children with cerebral palsy. Physical \& occupational therapy in pediatrics, 23(3), 31-50.

Tyler, N. B., \& Kahn, N. (1976). A home-treatment program for the cerebral-palsied child. American Journal of Occupational Therapy.

Wei, S., Su-Juan, W., Yuan-Gui, L., Hong, Y., Xiu-Juan, X., \& Xiao-Mei, S. (2006). Reliability and validity of the GMFM-66 in 0-to 3-year-old children with cerebral palsy. American journal of physical medicine \& rehabilitation, 85(2), 141-147.

mi H, Azizi R, Khayat Zade M. The effect of treatment environment on results of therapeutic motion along with restriction in children with cerebral palsy of hemiplegia. Mahname Daneshvar Pezeshki. Shahed University. 2010 ;18(19). 


$$
\text { مقالة يزوهشى }
$$

\section{بررسى تأثير درمان اختصاصى مبتنى بر مشاركت بر تحرك عملكردى كودكان مبتلا به فلج

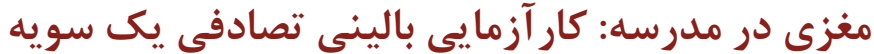

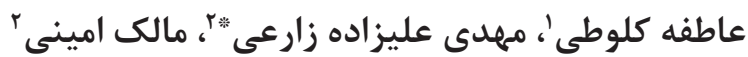

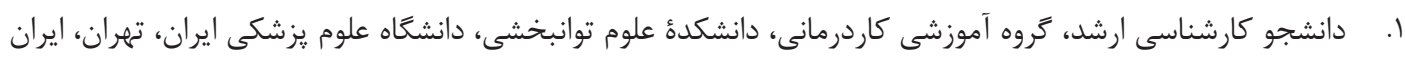

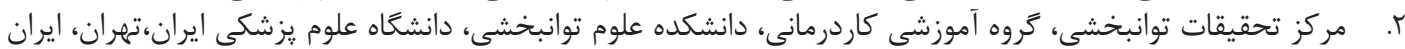

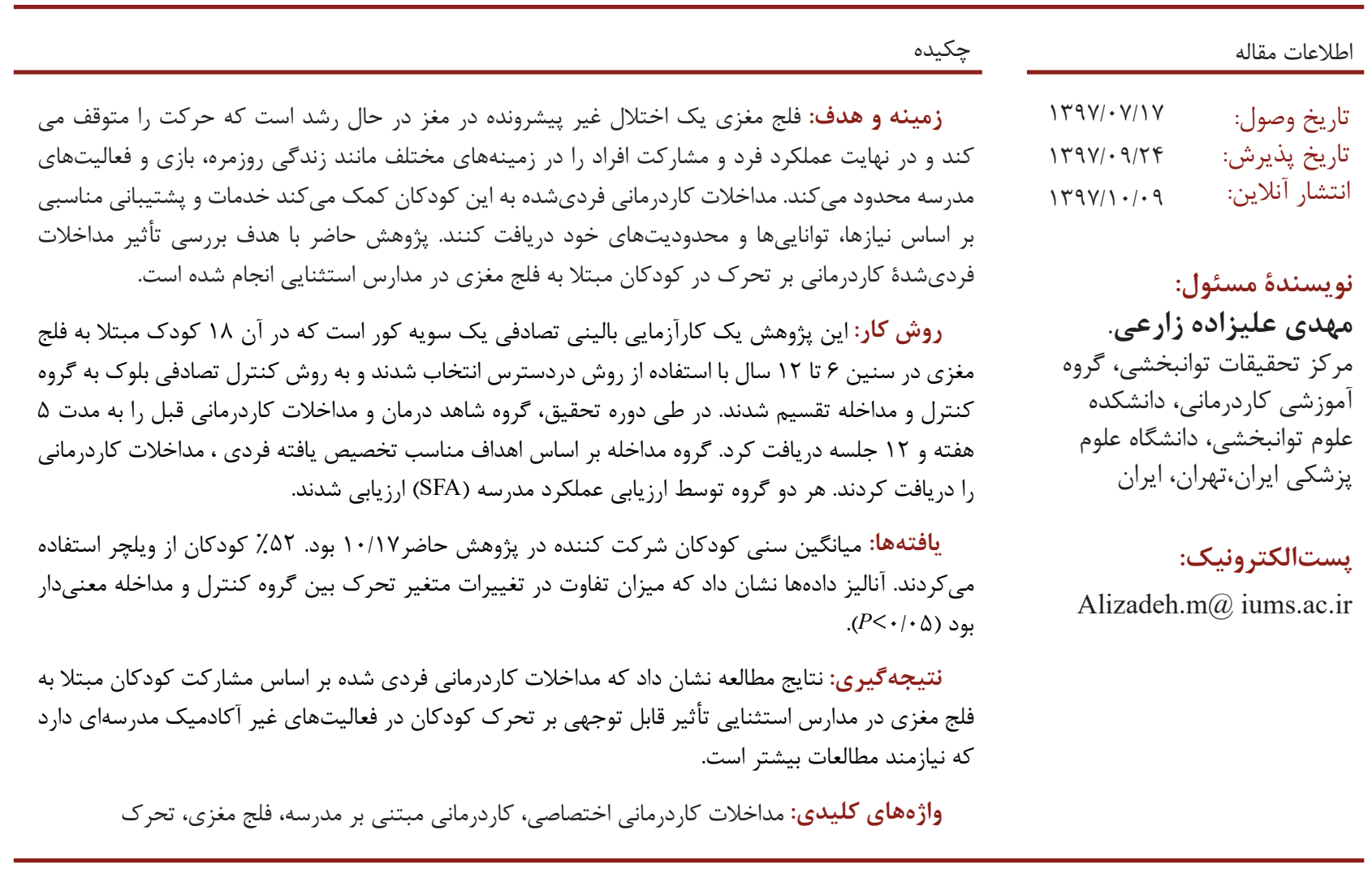

